\title{
Límites y alcances jurídicos sobre los derechos del nasciturus ${ }^{*}$
}

Martha Ximena Galvis Plazas ${ }^{* *}$

Fecha de recepción: 4 de diciembre de 2017

Fecha de evaluación: 18 de julio de 2018

Fecha de aprobación: 12 de septiembre de 2018

Artículo de reflexión

Resumen: El presente artículo, a través del análisis y la comparación de diferentes legislaciones, incluida la colombiana, tiene por objetivo presentar el conflicto que se da entre las posturas que, por un lado, reconocen al nasciturus en cualquier fase de su desarrollo como portador del derecho a la vida y, por otro lado, las que lo identifican únicamente como ser potencial que adquiere los derechos de una persona solo a partir del momento del nacimiento, incluido el derecho a la vida. Como conclusión, se determina que la ciencia del derecho ha aportado al significado y al rol del nasciturus, lo cual incide en el trato y en las responsabilidades y deberes no solo civiles, sino también morales que el Estado y las personas legalmente reconocidas tienen hacia él, sin embargo, en escenarios de guerra y violencia la realidad refleja desprotección y maltrato hacia el no nacido.

Palabras clave: derecho; nasciturus (no nacido); persona; violencia.

Cómo citar: Galvis, M. (2019). Límites y alcances jurídicos sobre los derechos del nasciturus. Revista Prolegómenos, 22(43), 93-107.

* Artículo resultado de la investigación: ¿El nasciturus como víctima? Vida prepersonal, dignidad y conflicto armado en Colombia, realizada para optar por el título de magistra en Bioética de la Pontificia Universidad Javeriana.

** Magistra en Bioética, especialista en Sistemas de Información y Gerencia de Documentos, licenciada en Ciencias Sociales. Actualmente es coordinadora de la Biblioteca Especializada del Instituto Colombiano de Antropología e Historia. Correo electrónico: martha.galvis@javeriana.edu.co 


\section{Limits and Legal Scope on Nasciturus Rights}

Abstract: Through an assessment and comparison of different laws, including Colombian legislation, this paper addresses conflicting positions that, on the one hand, recognize the nasciturus at any stage of its development as a bearer of the right to life, and, on the other hand, identify the unborn only as a potential human being who acquires personal rights, including the right to life, only as of birth. In conclusion, the author determines that the science of law has contributed to the meaning and role of nasciturus, which exerts an influence on its treatment, as well as on the civil and moral responsibilities borne by the State and other legally recognized entities; however, in scenarios of war and violence, reality reflects a lack of protection and mistreatment toward the unborn.

Keywords: Law; Nasciturus (Unborn); Person; Violence.

\section{Limites e alcance legal dos direitos do nascituro}

Resumo: Através da avaliação e comparação de diferentes leis, incluindo a legislação colombiana, este artigo aborda posições conflitantes que, por um lado, reconhecem o nascituro em qualquer estágio de seu desenvolvimento como um portador do direito à vida, e, por outro lado, identificam o feto apenas como um ser humano em potencial que adquire direitos como pessoa, incluindo o direito à vida, somente a partir do nascimento. Em conclusão, o autor determina que a ciência do direito contribuiu para o significado e papel do nascituro, o que exerce influência sobre o seu tratamento, bem como sobre as responsabilidades civis e morais assumidas pelo Estado e outras entidades legalmente reconhecidas; no entanto, em situações de guerra e violência, a realidade reflete uma falta de proteção e maus-tratos em relação aos não nascidos.

Palavras-chave: lei; nascituro (não nascido); pessoa; violência. 


\section{Introducción}

Hacia el nasciturus o no nacido apuntan interminables debates y discusiones que reflejan la falta de consenso en lo que respecta a los límites y alcances de los derechos que tiene o pudiera llegar a tener $y$, por consiguiente, a la protección que los diferentes actores en distintos roles tenemos hacia él y, para el caso particular, en aquellos escenarios que son de violencia y conflicto.

Por lo anterior, el propósito del presente artículo es reflejar el disenso y puntos de encuentro en lo que se refiere al significado, contexto y rol del nasciturus en diferentes épocas y legislaciones, con énfasis especial en la legislación colombiana, que al respecto se ha pronunciado ampliamente, como lo refleja, por citar un ejemplo, la Sentencia C-355 de 2006, que a su vez recoge los pronunciamientos, casos y situaciones de otros países y resuelve ciertas disposiciones que aplican al nasciturus, las cuales se resumen en la obligación del Estado de proteger la vida del no nacido aun cuando la garantía de sus derechos como persona se haga efectiva desde el nacimiento.

El análisis comparativo que aquí se presenta, entre las posturas que defienden que los derechos del nasciturus inician desde la concepción, en contraste con aquellas que plantean que los mencionados derechos solo son aplicables a partir del momento en que se empieza a disfrutar de la condición de persona, permite identificar que en Colombia la protección que el Estado ofrece al nasciturus es insuficiente ${ }^{1}$, porque no ha contemplado dentro de todas sus disposiciones las situaciones en las que por causas asociadas a la guerra el no nacido pierde la vida o padece alguna consecuencia por razones asociadas a ella. Bajo este contexto, se acude a la ciencia del derecho como referente conceptual y base para la discusión que queremos

1 Romeo (2002) plantea que existe una insuficiencia de los mecanismos jurídicos para proteger la vida del nasciturus que, de acuerdo con su contexto, es aplicable al caso chileno, pero que aplica también para otras partes del mundo. tratar, y también porque abre el espacio a otras disciplinas de las ciencias humanas, sociales y de las ciencias naturales que han contribuido con sus teorías, análisis y experiencias en lo que concierne al nasciturus.

\section{Obligaciones hacia el nasciturus en algunos escenarios del derecho}

Las leyes de cada país funcionan de acuerdo con referentes y principios legales del pasado que marcaron precedentes sobre la legislación contemporánea. Por esta razón, vale la pena conocer, a grandes rasgos, el lugar del nasciturus en algunos escenarios que influyeron de forma significativa en el pensamiento de Occidente y que son tenidos en cuenta hoy en día.

El propósito aquí no es listar una serie de legislaciones con amplitud en sus definiciones y consideraciones; tampoco se pretende decir que las mencionadas son las más importantes o que obedecen a alguna priorización. Más bien, se busca el acercamiento a la evolución del concepto de nasciturus y al rol que este desempeñaba en otros lugares y épocas para poder establecer la relación existente con su rol y significado en la actualidad ${ }^{2}$. Un punto de partida y de referencia que vale la pena destacar es la siguiente regla del derecho romano: "Infans conceptus pro nato habetur, quoties de commodis eius agitar" ("El concebido se tiene por nacido para todo lo que le sea favorable") ${ }^{3}$, la

\footnotetext{
2 Un punto de inicio que puede orientar esta discusión es la "Legislación de Partidas" originaria de Castilla, en el siglo XIII. Específicamente, en la Ley III, tít. XXIII, P. IV, se hace referencia de forma explícita al nasciturus. Alisté (2011) indica que esta ley es incluso hoy día tenida en cuenta como referente en las discusiones del derecho. Por su parte, Maldonado (1946), señala que la "Ley de Partidas" se considera una teoría completa del nasciturus, aunque fue de alguna manera modificada por las Leyes de Toro y por algunas disposiciones del siglo xvirI. En la "Ley de Partidas", el nasciturus aparece como un ser vivo, capaz de derechos, distinto e independiente de la madre en el aspecto jurídico.

3 Traducida en la Sentencia C-591 de 1995 de la Corte Constitucional de Colombia.
} 
cual por sí sola le concede al nasciturus un evidente privilegio.

Para cumplir el mencionado propósito, haremos referencia a Maldonado (1946) en su obra La condición jurídica del nasciturus, en la que presenta diferentes argumentos y situaciones en lo que respecta al no nacido en el derecho romano, el derecho germánico, el visigodo y el español de la Alta Reconquista ${ }^{4}$.

Sobre el derecho romano clásico, el autor indica que este no consideraba al nasciturus como persona jurídica perfecta ${ }^{5}$, pero reconocía en él la existencia de un sujeto de derechos en potencia, aunque estos fueran retrasados hasta el momento del nacimiento. En casos especiales, por ejemplo, cuando había un testamento del padre progenitor, la condición del concebido resultaba ser mejor que la de aquel que ya había nacido.

Bajo esta primera consideración, se debe tener en cuenta que las doctrinas cristianas influyeron mucho en la concepción del nasciturus del derecho romano. Maldonado (1946) indica que un ejemplo de ello fue San Agustín, quien expresó que en algún momento - el cual es imposible fijar de antemano- el concebido da cuenta de su

4 Otras legislaciones que se refieren al nasciturus, de otras latitudes, datan de fechas más antiguas que las legislaciones mencionadas, porque se ubican cronológicamente incluso a.C. Matthews y Benjamín (2004) al respecto presentan el Código Sumerio: art. 1. "Si un ciudadano golpea accidentalmente a la hija de otro, y ésta aborta, entonces la multa será de diez siclos [80 gr] de plata” (p. 99); el Código Hammurabi: art. 209. "Si un ciudadano golpea a la hija de otro y le causa un aborto, entonces la multa será de diez siclos [80 gr] de plata" (p. 108); y el Código Mesoasirio: art. 50. "Si un ciudadano maltrata físicamente a la esposa de otro hasta que tiene un aborto, entonces el marido de ésta maltratará físicamente de la esposa del acusado hasta que tenga un aborto. El acusado compensará a la víctima dando a la familia de ésta un hijo de su propia familia” (p. 121).

5 Podría interpretarse que sería más bien una persona jurídica imperfecta. De acuerdo con De Castro y Bravo (1991), este tipo de personas no logran independencia completa, ni en su gestión ni en su patrimonio, respecto del Estado o de sus socios. vida propia independiente de la vida de su madre, por lo que podría considerársele como ser autónomo. De esto se desprende que desde la doctrina cristiana el aborto sea castigado, porque cuando se condena a muerte al concebido desde antes de nacer el fundamento de la condena estará en la personalidad misma del nuevo ser.

Por otra parte, en el derecho germánico no se consideraba al nasciturus como sujeto de derechos, sino privado de toda capacidad de razón, por lo que su vida se podía destruir sin ningún castigo; sin embargo, debido a la influencia cristiana y romana, en la Lex Salica ${ }^{6}$ y en el Pactus Alamannorum ${ }^{7}$ del siglo viI se establecieron penas a quienes causaran la muerte al feto en el seno materno.

En cuanto al derecho visigodo, el autor menciona que la protección jurídica en la legislación se extendía a los concebidos. Dicha protección se evidenció en diferentes textos de la época que castigaban el aborto y en otros donde se le concedía al no nacido derechos hereditarios en el caso de la muerte de su padre, con el propósito de salvaguardar la vida del nasciturus o sus futuros derechos patrimoniales.

Otros escritos de esta corriente ${ }^{8}$ también mencionan los duros castigos a los cuales eran sometidos los padres que intentaran o produjeran la muerte del concebido. Dichos castigos iban desde producirle la ceguera hasta la misma

6 "Ley Sálica fue un código legal redactado en latín y promulgado el 10 de mayo de 1703, compilado por vez primera en el siglo vi por los salios (parte del pueblo germánico de los francos) que habían conquistado la Galia (Europa Occidental) en el siglo v. El documento incluye principalmente las multas que habían de pagarse por ofensas y delitos”. Recuperado de http://co.tuhistory.com.

7 "The term Pactus Alamannorum denotes a fragment of an older Alemannic law book that only survives in Paris Lat. 10753. According to the communis opinion the short penitential catalogue dates back to the time of the Merovingian king Chlothar II. (584-628/9)". Recuperado de http://www.leges. uni-koeln.de

8 Dentro de dichos escritos se resaltan los de Chisdanvinto: rey visigodo de Toledo entre los años 642 y 653 . 
muerte, negando claramente cualquier derecho de los padres sobre la vida del nasciturus.

Finalmente, en la relación del derecho y el nasciturus, Maldonado (1946) hace referencia al derecho español de la Alta Reconquista, el cual comprende tres aspectos: la prohibición del aborto causado por los padres, la configuración de un homicidio independiente en los casos de muerte violenta del feto; y las medidas para evitar que el hijo que se encuentra en el vientre de la madre sufra por las medidas impuestas a ella.

Sobre el segundo aspecto, quien le causara la muerte a una mujer encinta se consideraría culpable de doble homicidio, se duplicaría la gravedad de la falta y, a su vez, se consideraría culpable de dos delitos distintos. De la misma forma, en las situaciones en las cuales una herida causada a una mujer embarazada generase la muerte del hijo, a diferencia del caso anterior, no se duplicarían las consecuencias del acto, pero sí se tratarían las dos situaciones como independientes.

Los ejemplos de las legislaciones brevemente descritas nos permiten afirmar que el nasciturus ha sido importante y ha ocupado un lugar en lo que respecta a la organización social y a la distribución económica dentro de la familia; también que su definición y rol está influenciado por la concepción religiosa. Además, se muestra que, desde los orígenes del derecho en Occidente, se encuentra el concepto de potencialidad del nasciturus como objeto de protección jurídica, y se carga con responsabilidades a quienes producen su muerte o atentan contra su vida, a la cual se le debe cuidar y proteger.

Al mismo tiempo, las anteriores legislaciones abordadas llevan a la discusión en torno a quiénes son o deben ser considerados personas y quiénes no lo son. Hoyos (2000), por su parte, plantea una relación entre el concepto jurídico de persona con el concepto filosófico:

El concepto jurídico de persona, tiene relación con el concepto filosófico de persona. Uno y otro concepto se refieren a la misma realidad: el ser humano, aunque las notas que se resalten sean distintas, porque el saber jurídico no estudia la persona $s u b$ ratione personalitatis, según la razón misma de la persona, sino sub ratione iustitiae, según la razón de la justicia. Estos contenidos de justicia no son, sin embargo, ajenos a la persona; por el contrario, son inherentes a su realidad ontológica. Así, puede decirse que la persona no es un ser creado por el derecho: es preexistente a él y, en cuanto tal, es un ser ante el derecho (pp. 64-65).

Por su parte, Montoya (2004) indica que surge el interrogante sobre cómo considerar jurídicamente al nasciturus teniendo en cuenta que la personalidad jurídica se entiende como la posibilidad de ser centro de imputación; es decir, la posibilidad de adquirir derechos y obligaciones y ser parte en una imputación jurídica, condiciones que se adquieren desde el nacimiento. De esta forma, en Colombia los estatutos jurídicos estimaron que el que está por nacer no puede considerarse persona, sin embargo, buscando su protección, estableció un estatuto especial para el nasciturus y adicionalmente el derecho penal, estableció los tipos penales para las acciones que atentaran contra el desarrollo de la gestación.

Corral (2017) presenta una posición filosófica para explicar el valor que se le debe asignar al nasciturus del cual coligen sus potenciales o firmes derechos:

En términos kantianos, el embrión humano no es una cosa sujeta a valoración cuantitativa (precio), sino una persona de valor absoluto e incomensurable (dignidad). Esta lectura - digamos finalmente- es la única compatible con el derecho de todo ser humano a que se reconozca su estatus jurídico de persona, derecho que ha sido declarado expresamente por la Convención Americana de Derechos Humanos o Pacto de San José de Costa Rica (art. 3, en relación con el art. 1.2).

Es en este contexto donde se interrelacionan diferentes elementos que vinculan al derecho con la protección del nasciturus, como lo plantea Díaz (2006): 
Si se concentra la protección en el organismo, considerado como bien jurídico en función de las fases de su desarrollo, se desconoce el ser profundo de la vida, que extravasa la categoría de cosa, pues su identidad no está clausurada dentro de unos límites fijados de antemano en una disposición legal (pp. 199-200).

De forma más enfática en lo relacionado con la protección del nasciturus, Ugarte (2017) hace referencia al aborto como una forma de afectación del derecho a la vida:

El aborto es intrínsecamente malo, porque atropella el derecho a la vida del embrión o feto, haciendo ver $\mathrm{I}^{\circ}$ ) que este es persona humana desde la concepción, y $\mathrm{II}^{\circ}$ ) que el darle muerte en estos casos es directamente un homicidio, que no puede nunca justificarse.

Sobre el tema del aborto, Starck (2006) también es enfático al afirmar que la vida humana del no nacido no ha sido protegida expresamente en los convenios internacionales sobre derechos humanos, aunque se deduce de algunos textos al respecto. Dentro de ellos está el art. 2 de la Convención Europea para la Protección de los Derechos Humanos y las Libertades Fundamentales del 4 de noviembre de 1950, que plantea el derecho de todo ser humano a la vida, pero no es explícita la extensión de este derecho a los embriones, frente a lo cual el Tribunal Europeo de Derechos Humanos para 2006 aún no se había pronunciado.

De la misma forma, el Tribunal Constitucional de Alemania, en sus dos sentencias sobre el aborto de 1975 y 1993, afirma que la vida del ser humano no nacido queda también bajo la protección de la garantía de la dignidad humana, lo que lleva implícito considerar al no nacido como un ser humano que a su vez posee intereses propios y que disfruta de la protección desde el momento de la anidación. De la misma forma, la interrupción del embarazo que no fuera indicada médicamente es consideraba antijurídica y por tanto prohibida.

Sobre la variedad de definiciones del nasciturus y de persona, en gran medida con una influencia del derecho, Cárdenas y Sierra-Torres
(2004) plantean que se podrían definir tres tipos de definición legal de persona de acuerdo con las variadas posiciones entre los ordenamientos jurídicos mundiales sobre lo que es el nasciturus, el momento en que inicia la existencia de la persona, los derechos que se le otorgan y en los que sería titular a nivel legal. La primera definición, basada en los ordenamientos jurídicos en los cuales la persona existe desde la concepción; la segunda, basada en aquellos ordenamientos en los cuales se es persona a partir del nacimiento con vida; y la tercera, basada en los ordenamientos jurídicos mixtos en los cuales es persona todo ser humano que nace vivo, pero al nasciturus se le otorgan algunos derechos que le garantizan su protección y respeto por sus derechos fundamentales.

Franca-Tarragó (2008) precisa sobre la necesidad de distinguir diferentes niveles o perspectivas en la vida de un individuo de la especie humana. En este sentido, menciona tres niveles: el biológico, ontológico-ético y el jurídico, que reconoce a alguien como portador de apariencia de individuo humano y merecedor de los mismos derechos de los otros, de acuerdo con las características admitidas por una convención social y positivadas por el sistema jurídico.

\section{El nasciturus en el contexto legal colombiano}

A partir del significado y valor que se le asigna al nasciturus en cada contexto y en cada legislación, surgen en torno a él los elementos que argumentan y justifican su protección. Sin embargo, tenemos en cuenta la precisión que hace Porras del Corral (2005) en relación con los límites y alcances del derecho, el cual "debe impulsar y coadyuvar a cuanto contribuya a desarrollar las potencialidades del hombre como ser humano" (p. 211). El papel del Estado sobre este asunto es decisivo, porque a partir de sus disposiciones se establecen oficialmente las acciones de los ciudadanos en favor 
de la protección hacia el no nacido y las sanciones correspondientes?.

El Estado colombiano en cumplimiento de la Constitución Política está en la obligación de intervenir en asuntos del individuo y la comunidad, en lo que se refiere a sus derechos y deberes. Las leyes, con sus diferentes mecanismos, en pro de hacer efectivo el pronunciamiento de la Carta Fundamental en la que se declara a Colombia como democrática, participativa y pluralista, propician el debate entre los ciudadanos colombianos y se apoyan en algunos elementos de legislaciones extranjeras para establecer recomendaciones, normas o sanciones, sobre temas tan controversiales como la protección de la vida humana, los derechos humanos, el aborto, entre otros.

Precisamente, acerca del tema del aborto se ha abierto un debate interminable sobre el cual la legislación colombiana se ha pronunciado en diferentes ocasiones. Parte del contenido de este debate surge de la interpretación que se le da al artículo 11 de la Constitución Política de Colombia (1991): "El derecho a la vida es inviolable, no habrá pena de muerte". De esta afirmación se desprende la controversia sobre cuándo comienza la vida humana, el estatus de persona del no nacido y el alcance que tendría para el nasciturus el derecho a la vida.

La legislación colombiana se ha referido al nasciturus en diferentes sentencias, leyes y decretos que en ocasiones son derogados por otros y que con frecuencia tratan el tema del aborto. A continuación se indican algunos de ellos.

\section{Código Civil Colombiano ${ }^{10}$}

Los cuatro artículos que hacen mención al nasciturus clarifican los límites y alcances del derecho en relación con él:

Artículo 90. Existencia legal de las personas. La existencia legal de toda persona principia al nacer, esto es, al separarse completamente de su madre. La criatura que muere en el vientre materno, o que perece antes de estar completamente separada de su madre, o que no haya sobrevivido a la separación un momento siquiera, se reputará no haber existido jamás.

Artículo 91. Protección al que está por nacer. La ley protege la vida del que está por nacer. El juez, en consecuencia, tomará, a petición de cualquiera persona, o de oficio, las providencias que le parezcan convenientes para proteger la existencia del no nacido, siempre que crea que de algún modo peligra.

Artículo 92. Presunción de derecho sobre la concepción. De la época del nacimiento se colige la de la concepción, según la regla siguiente: se presume de derecho que la concepción ha precedido al nacimiento no menos que ciento ochenta días cabales, y no más que trescientos, contados hacia atrás, desde la media noche en que principie el día del nacimiento.

Artículo 93. Derechos diferidos al que está por nacer. Los derechos que se diferirían a la criatura que está en el vientre materno, si hubiese nacido y viviese, estarán suspensos hasta que el nacimiento se efectúe. $\mathrm{Y}$ si el nacimiento constituye un principio de existencia, entrará el recién nacido en el goce de dichos derechos, como si hubiese existido al tiempo en que se defirieron. En el caso del inciso del artículo 90 pasarán estos derechos a otras personas, como si la criatura no hubiese jamás existido.

Lo planteado en el Código Civil amplia el espectro sobre los límites y alcances de la existencia legal y los derechos del nasciturus, así como la tensión que genera entre quienes reconocen la

9 Esto no quiere decir que estas disposiciones del Estado son las únicas que garantizan las acciones de los ciudadanos en favor de la protección del nasciturus. Las acciones de los ciudadanos con fundamentos morales y convicciones sobre la importancia de la vida humana resultan ser fundamentales.
10 Lo relacionado con el nasciturus en el Código Civil Colombiano, se encuentra en el Título II, Del principio y fin de la existencia de las personas, Capítulo I - Del principio de la existencia de las personas, artículos 90-93. 
titularidad de derechos al no nacido y los que no. A su vez, el Código Civil colombiano, basándose en la Constitución, refiere una protección especial al nasciturus por su vulnerabilidad y, aunque no lo reconoce como persona, estipula compromisos y obligaciones de todas las personas hacia él.

\section{Decreto Ley 100 de 1980 (derogado por la Ley 599 de 2000)}

Artículo 343. Aborto. La mujer que causare su aborto o permitiere que otro se lo cause, incurrirá en prisión de uno a tres años. A la misma sanción estará sujeto quien, con el consentimiento de la mujer, realice el hecho previsto en el inciso anterior.

Artículo 344. Aborto sin consentimiento. El que causare el aborto sin consentimiento de la mujer o en mujer menor de catorce años, incurrirá en prisión de tres a diez años.

Artículo 345. Circunstancias específicas. La mujer embarazada como resultado de acceso carnal violento, abusivo o de inseminación artificial no consentida que causare su aborto o permitiere que otro se lo cause, incurrirá en arresto de cuatro meses a un año. En la misma pena incurrirá el que causare el aborto por estas circunstancias.

\section{Sentencia n. ${ }^{\circ}$ C-133 de 1994}

Es cierto que nuestra Constitución Política reconoce expresamente el derecho inviolable a la vida a quienes son personas pertenecientes al género humano; pero de allí no se sigue que la vida humana latente en el nasciturus, carezca de protección constitucional. En efecto, si el valor esencial protegido por el ordenamiento superior es la vida humana, necesariamente debe colegirse que en donde haya vida, debe existir el consecuente amparo estatal.

En otros términos, la Constitución no solo protege el producto de la concepción que se plasma en el nacimiento, el cual determina la existencia de la persona jurídica natural, en los términos de las regulaciones legales, sino el proceso mismo de la vida humana, que se inicia con la concepción, se desarrolla y perfecciona luego con el feto, $y$ adquiere individualidad con el nacimiento.
(...) La vida del nasciturus encarna un valor fundamental, por la esperanza de su existencia como persona que representa, y por su estado de indefensión manifiesto que requiere de la especial protección del Estado.

\section{Sentencia - $^{\circ}$ C-013 de 1997}

En criterio de esta Corte, la vida que el Derecho reconoce y que la Constitución protege tiene su principio en el momento mismo de la fecundación y se extiende a lo largo de las distintas etapas de formación del nuevo ser humano dentro del vientre materno, continúa a partir del nacimiento de la persona y cobija a ésta a lo largo de todo su ciclo vital. (...) Ningún criterio de distinción es aceptable, a la luz del Derecho, para suponer que esa protección constitucional tenga vigencia y operancia únicamente a partir del nacimiento de la persona, o que deba ser menos intensa durante las etapas previas al alumbramiento.

\section{Sentencia T-223 de $1998^{11}$}

El grupo, los llamados nasciturus, se encuentra protegido por el espectro de privilegios que la Carta Fundamental reserva para los niños. La tradición jurídica más acendrada, que se compagina con la filosofía del Estado social de derecho, ha reconocido que el nasciturus es sujeto de derechos en cuanto es un individuo de la especie humana. Los innumerables tratados y convenios internacionales suscritos por Colombia, así como el preámbulo de la Constitución Política, cuando asegura que el Estado tiene la obligación de garantizar la vida de sus integrantes; el artículo 43, al referirse a la protección de la mujer embarazada, y el artículo 44, cuando le garantiza a los niños el derecho a la vida, no hacen otra cosa que fortalecer la premisa de que los individuos que aún no han nacido, por la simple calidad de ser humanos, tienen garantizada desde el momento mismo

11 La aclaración de voto de esta sentencia presentada por la magistrada Carmenza Isaza indica que no era necesario el análisis que se realiza en ella sobre los derechos del nasciturus, debido a que quien interpone la demanda reclamaba los derechos que se estaban vulnerando de una persona que ya había nacido y no los de quien no había nacido. 
de la concepción la protección de sus derechos fundamentales. La Constitución busca preservar al no nacido en aquello que le es connatural y esencial: la vida, la salud, la integridad física, etc. Sin embargo, debe tenerse en cuenta que un principio lógico de razonabilidad exige considerar en particular cada uno de los derechos fundamentales, incluso aquellos que se predican exclusivamente de los niños, para determinar cuál puede y cuál no puede ser exigido antes del nacimiento.

Los derechos patrimoniales de orden legal que penden sobre el nasciturus, se radican en cabeza suya desde la concepción, pero sólo pueden hacerse efectivos, sí y solo sí, acaece el nacimiento. Por el contrario, los derechos fundamentales pueden ser exigibles desde el momento mismo que el individuo ha sido engendrado.

\section{Ley 599 de 2000 (Código Penal colombiano)}

Artículo 118. Parto o aborto preterintencional. Si a causa de la lesión inferida a una mujer, sobreviniere parto prematuro que tenga consecuencias nocivas para la salud de la agredida o de la criatura, o sobreviniere el aborto, las penas imponibles según los artículos precedentes, se aumentarán de una tercera parte a la mitad.

Artículo 122. Aborto. La mujer que causare su aborto o permitiere que otro se lo cause, incurrirá en prisión de uno (1) a tres (3) años. A la misma sanción estará sujeto quien, con el consentimiento de la mujer, realice la conducta prevista en el inciso anterior.

Artículo 123. Aborto sin consentimiento. El que causare el aborto sin consentimiento de la mujer o en mujer menor de catorce años, incurrirá en prisión de cuatro (4) a diez (10) años.

Artículo 124. Circunstancias de atenuación punitiva. La pena señalada para el delito de aborto se disminuirá en las tres cuartas partes cuando el embarazo sea resultado de una conducta constitutiva de acceso carnal o acto sexual sin consentimiento, abusivo, de inseminación artificial o transferencia de óvulo fecundado no consentidas.
Artículo 125. Lesiones al feto. El que por cualquier medio causare a un feto daño en el cuerpo o en la salud que perjudique su normal desarrollo, incurrirá en prisión de dos (2) a cuatro (4) años. Si la conducta fuere realizada por un profesional de la salud, se le impondrá también la inhabilitación para el ejercicio de la profesión por el mismo término.

Artículo 126. Lesiones culposas al feto. Si la conducta descrita en el Artículo anterior se realizare por culpa, la pena será de prisión de uno (1) a dos (2) años. Si fuere realizada por un profesional de la salud, se le impondrá también la inhabilitación para el ejercicio de la profesión por el mismo término.

\section{Sentencia.$^{\circ}$ C-355 de 2006}

Recoge la mayoría de las sentencias y leyes mencionadas anteriormente y marca un precedente importante en la historia del país en lo que corresponde al polémico tema del aborto. Por supuesto, hace mención de manera amplia del significado y rol que se le concede al nasciturus no solo en la legislación colombiana, sino también en otras que aportan en la conclusión de la Corte. De acuerdo con el fallo el artículo 122 del Código Penal es exequible siempre y cuando se excluyan, si la mujer así lo decide, estas causales:

a) cuando la continuación del embarazo represente peligro para la vida o la salud de la mujer,

b) cuando se presente malformación en el feto que no haga viable su vida $y$,

c) cuando el embarazo sea el producto de acceso carnal abusivo, inseminación artificial, transferencia de óvulo fecundado sin consentimiento o incesto.

Por tanto, la prohibición absoluta del aborto es considerada inconstitucional. Adicionalmente, la sentencia declara inexequible el artículo 124 del mismo código y, en otras disposiciones, se refiere a los derechos de la mujer, cambiando de forma significativa lo que en Colombia se había dispuesto sobre el aborto.

De la misma forma, la sentencia presenta de forma explícita los siguientes puntos que ayudan a aclarar el significado y rol que tiene actualmente para la legislación colombiana el nasciturus: 
- Es obligación constitucional que el Estado brinde protección al concebido y en ningún momento se la niegue.

- El nasciturus no es considerado una persona humana como tal y, aunque merece protección, esta es jurídicamente distinta a la que se le debe brindar a quienes sí poseen dicho estatus de acuerdo con el ordenamiento constitucional colombiano.

- Existe una diferencia entre el derecho a la vida y la vida como bien protegido por la Constitución $y$, por tanto, diferentes tratamientos normativos.

- Sobre el derecho a la vida supone la titularidad para su ejercicio y está restringida a la persona humana.

Existe una distinción entre la protección especial al embrión o feto y la protección general del derecho a la vida de la persona humana. Uno representa el ser como tal y el otro la potencialidad de ser.

La protección de la vida alcanza incluso hasta quienes no han adquirido la condición de persona humana.

Aunque constitucionalmente el derecho a la vida tiene un gran peso, este no es de carácter absoluto y debe ser confrontado con los demás valores, principios y derechos de la Constitución.

El problema del aborto radica en la tensión que existe entre la vida de la madre y el que está por nacer. Prevalece la vida de la madre que posee la condición de persona y por tanto el derecho a su vida y su dignidad.

Por otro lado, la Sentencia C-355 de 2006 menciona tratados y convenios internacionales que tienen alcance en lo que concierne al nasciturus y que soportan las consideraciones a favor y en contra de las normas demandadas en la Sentencia y también las de la Corte, dejando ver una vez más que la interpretación jurídica está situada en contextos sociales y jurídicos específicos. Algunas de estas disposiciones del derecho internacional hacen parte del bloque de constitucionalidad. Al respecto, la sentencia precisa: [de ellas] no se desprende un deber de protección absoluto e incondicional de la vida en gestación; por el contrario, tanto de su interpretación literal como sistemática surge la necesidad de ponderar la vida en gestación con otros derechos, principios y valores reconocidos en la Carta de 1991 y en otros instrumentos del derecho internacional de los derechos humanos, ponderación que la Corte Interamericana de Derechos Humanos ha privilegiado (p. 241).

Dentro de este grupo, destacamos las siguientes: Pacto Internacional de Derechos Civiles y Políticos: Artículo 6‥ 1. "El derecho a la vida es inherente a la persona humana. Este derecho estará protegido por la ley. Nadie podrá ser privado de la vida arbitrariamente".

Declaración Americana de los Derechos y Deberes del Hombre: "Artículo $1^{\circ}$.- Derecho a la vida, a la libertad, a la seguridad e integridad de la persona"12.

Convención Americana sobre derechos humanos suscrita en San José de Costa Rica, aprobada por Colombia mediante la Ley 16 de 197213: "Artículo $4^{\circ}$.- 1 . Toda persona tiene derecho a la vida. Este derecho estará protegido por la ley y, en general, a partir del momento de la concepción. Nadie podrá ser privado de la vida arbitrariamente".

Convención sobre los Derechos del Niño: "Preámbulo [...] el niño, por su falta de madurez física y mental, necesita protección y cuidados especiales, incluida la debida protección legal, tanto antes como después del nacimiento". "Artículo 6.- 1. Los Estados Partes reconocen que todo niño tiene el derecho intrínseco de la vida”.

12 Sobre esta declaración, surge una discusión más ya que por las palabras que la componen, se podría interpretar que todos los hombres que hacen parte de la especie humana son personas.

13 El contenido de la expresión "a partir del momento de la concepción" de esta Convención da lugar a una demanda del artículo 90 del Código Civil Colombiano, por lo que la Corte Constitucional Colombiana se pronuncia través de la Sentencia n. ${ }^{\circ}$ C- 327 de 2016. 
Convenio de Ginebra de 1949: "Artículo 3.- A este respecto, [actores ajenos al conflicto armado] se prohíben... a) Los atentados contra la vida y la integridad corporal, especialmente el homicidio en todas sus formas, las mutilaciones, los tratos crueles, la tortura y los suplicios".
En efecto, podemos reconocer elementos muy útiles en las convenciones, declaraciones y pactos enunciados. En primer lugar, sobresale el derecho a la vida y su conexión con la libertad, la seguridad y la integridad. En segundo lugar, la garantía de protección de dicho derecho se extiende desde

Tabla 1. Posiciones a favor y en contra de la despenalización del aborto por las tres causales

Consideraciones de la Corte

Salvamentos de voto*

La vida

Un bien jurídico vs. un derecho subjetivo fundamental

La vida humana transcurre en distintas etapas y se manifiesta de diferentes formas, las que a su vez tienen una protección jurídica distinta. El ordenamiento jurídico, si bien es verdad, que otorga protección al nasciturus, no la otorga en el mismo grado e intensidad que a la persona humana. Tanto es ello así, que en la mayor parte de las legislaciones es mayor la sanción penal para el infanticidio o el homicidio que para el aborto. Es decir, el bien jurídico tutelado no es idéntico en estos casos y, por ello, la trascendencia jurídica de la ofensa social determina un grado de reproche diferente y una pena proporcionalmente distinta (...). (p. 3)
(...) Consideramos constitucionalmente inaceptable la distinción planteada en la Sentencia, según la cual la vida del ser humano no nacido es tan sólo un "bien jurídico", al paso que la vida de las personas capaces de vida independiente sí constituye un derecho subjetivo fundamental. A nuestro parecer, la vida humana que aparece en el momento mismo de la concepción constituye desde entonces y hasta la muerte un derecho subjetivo de rango fundamental en cabeza del ser humano que la porta, y en ningún momento del proceso vital puede ser tenida solamente como un "bien jurídico", al cual pueda oponerse el mejor derecho a la vida 0 a la libertad de otro ser humano. (p. 563)

\section{¿Cuándo inicia la vida humana?}

(...) Determinar el momento exacto a partir del cual se inicia la vida humana es un problema al cual se han dado varias respuestas, no sólo desde distintas perspectivas como la genética, la médica, la religiosa, o la moral, entre otras, sino también en virtud de los diversos criterios expuestos por cada uno de los respectivos especialistas, y cuya evaluación no le corresponde a la Corte Constitucional en esta decisión (p. 3).

Los datos científicos que demuestran que la vida humana empieza con la concepción o fertilización ya habían sido admitidos por esta Corporación como conclusiones válidas obtenidas por la ciencia contemporánea. Ciertamente, como se vio, en la Sentencia C-133 de 1994 la Corte había definido que la vida humana comienza con la concepción y que desde ese momento merece protección estatal; y lo había hecho con base en datos científicos que sirvieron de fundamento probatorio a la providencia. Por lo cual, sostener lo contrario en una Sentencia posterior, cambiando el sentido de la jurisprudencia, exigía desplegar una carga argumentativa científicamente soportada, que demostrara claramente que la vida humana no empieza en ese momento, cosa que no hizo la Sentencia (pp. 563-564).

\section{Nasciturus}

No tiene personalidad jurídica vs. Posee titularidad de derechos

De aceptarse una tesis contraria, esto es, que el nasciturus tiene personalidad jurídica sus derechos siempre prevalecerían sobre el de la madre: un ser que no expresó su voluntad para venir al mundo y que además está indefenso; enfrentado a quien la trajo al mundo sin su voluntad y con más poder que el feto, en caso de conflicto, deberían primar los derechos del más débil.

La consecuencia de aceptar que el nasciturus tiene personalidad jurídica; es tanto como permitir que exista una persona que solo tiene derechos pero que no tiene obligaciones o deberes jurídicos, lo que sería contradictorio con el concepto mismo de personalidad jurídica, que implica derechos y deberes u obligaciones.

En este orden de ideas, la confrontación existente debe plantearse entre la madre que tiene personalidad jurídica y derechos ciertos y actuales, frente a un ser que carece de personalidad jurídica, que no tiene derechos subjetivos y que solo es objeto de prestaciones (y que por lo tanto solamente posee potencialidades) (pp. 312-313) ${ }^{\star *}$.
Visto pues que el nasciturus es individuo de la especie humana y que por lo tanto posee plena titularidad de derechos, siendo entonces persona en sentido jurídico, forzoso era concluir que el Estado estaba en la obligación constitucional de proteger su vida como derecho subjetivo y fundamental en cabeza suya, pues al tenor de la Carta "las autoridades de la República están instituidas para proteger a todas las personas residentes en Colombia, en su vida (...) (p. 605). 
Aborto

Despenalización vs. Penalización

Empero, si bien no resulta desproporcionada la protección del nasciturus mediante medidas de carácter penal y en consecuencia la sanción del aborto resulta ajustada a la Constitución Política, la penalización del aborto en todas las circunstancias implica la completa preeminencia de uno de los bienes jurídicos en juego, la vida del nasciturus, y el consiguiente sacrificio absoluto de todos los derechos fundamentales de la mujer embarazada, lo que sin duda resulta a todas luces inconstitucional.

En efecto, a juicio de esta Corporación, ésta debe ser una de las hipótesis bajo las cuales debe considerarse que la interrupción del embarazo no es constitutiva de delito de aborto, no sólo por la manera como fue inicialmente contemplada por el legislador sino también porque en este caso la prevalencia absoluta de la protección de la vida del nasciturus supone un total desconocimiento de la dignidad humana y del libre desarrollo de la personalidad de la mujer gestante, cuyo embarazo no es producto de una decisión libre y consentida sino el resultado de conductas arbitrarias que desconocen su carácter de sujeto autónomo de derechos y que por esa misma razón están sancionadas penalmente en varios artículos del Código Penal (p. 285).
[Sobre el riesgo para la vida y salud de la madre]:

En el aborto terapéutico la causa del actuar del agente que lo provoca, esto es el riesgo de muerte que padece la madre, no resulta proporcionada al daño cierto que se verifica en la esfera de los derechos del no nacido. Así, el aborto en este caso constituye un daño mayor, porque la elección se hace entre un daño cierto y un daño eventual. Lo anterior revela que detrás de la práctica de esta forma de aborto lo que verdaderamente subyace es la utilización de la vida del feto para erradicar el riesgo de muerte de la madre. En efecto, si la vida para el viviente es su mismo ser, el aborto terapéutico implica la utilización de un ser humano para los fines de otro, lo cual equivale a desigualar el derecho a la vida de la madre frente al derecho a la vida del hijo, concediéndole preponderancia al primero de estos derechos. El aborto terapéutico, así visto, se erige en un atentado contra la igualdad (p. 570).

[Sobre malformaciones en el feto que hagan inviable su vida]: La Corte ha estimado que causar la muerte a otro movido por la piedad puede estar justificado. Empero, ha exigido que para que se configure tal causal de justificación, debe estar de por medio "la voluntad libre del sujeto pasivo del acto". Es más, ha puesto énfasis en que deben existir regulaciones "destinadas a asegurar que el consentimiento sea genuino". Visto lo anterior, debe estimarse que no es posible asimilar el homicidio pietístico justificado (eutanasia consentida) al aborto que se practica en caso de detección de malformaciones genéticas, pues en este último el sujeto pasivo de la acción (el feto), no ha dado su consentimiento ni está en condiciones de hacerlo, sin que tampoco pueda razonablemente entenderse que su progenitora puede consentir por él, en asunto tan fundamental como el concerniente a la disposición de su vida (p. 571).

[Y sobre el aborto en caso de violación, transferencia de óvulo 0 inseminación no consentida]:

Ciertamente, como se dijo anteriormente, el embarazo forzado producto de violación, inseminación artificial o trasferencia de óvulo no consentida constituyen delitos que atengan contra este derecho fundamental de las mujeres. Sin embargo, es menester tener en claro que el sujeto causante de la violación de derechos mencionada no es el Estado que en defensa del derecho a la vida del no nacido, y por las razones de jerarquización y ponderación de derechos que se acaban de estudiar, decide penalizar el aborto, sino el agente del delito. Como tampoco lo es el ser humano concebido como fruto de la comisión de la conducta ilícita, cuya vida se protege con la penalización mencionada. Por las obvias razones anteriores, la penalización de aborto en los casos anteriores no elimina el derecho a la autodeterminación reproductiva de la mujer. Simplemente implica que dicho derecho no puede ser exigible aun a costa de la vida del ser humano concebido como fruto de un accionar delictivo (p. 572) ${ }^{* * *}$. 
[La dignidad humana como límite]:

La dignidad humana se constituye así en un límite a la potestad de configuración del legislador en materia penal, aun cuando se trate de proteger bienes jurídicos de relevancia constitucional como la vida. En tal medida, el legislador al adoptar normas de carácter penal, no puede desconocer que la mujer es un ser humano plenamente digno y por tanto debe tratarla como tal, en lugar de considerarla y convertirla en un simple instrumento de reproducción de la especia humana, o de imponerle en ciertos casos, contra su voluntad, servir de herramienta efectivamente útil para procrear (p. 6).

(...) la Corte ha entendido que el enunciado normativo "dignidad humana", desempeña tres roles distintos: (i) es un principio fundante del ordenamiento jurídico y en este sentido tiene una dimensión axiológica como valor constitucional, (ii) es un principio constitucional y (iii) tiene el carácter derecho fundamental autónomo. (p. 255)
En el lenguaje corriente, hablar de dignidad supone hacer referencia a un especial merecimiento que se deriva de un estatus de superioridad; a una exigencia que emana directamente de la especial condición del sujeto. En este sentido, la expresión dignidad humana, consagrada en el artículo primero de la Constitución Política, en su sentido natural y obvio se refiere a una forma de dignidad intrínseca que se tiene en virtud de la condición humana. Es decir, el reconocimiento de la dignidad humana debe entenderse como la constatación de una valía propia del ser humano, que existe con independencia de la condición en que éste se encuentre y del mérito de sus acciones.

En síntesis, los salvamentos de voto indican que la dignidad humana es inherente a la condición humana, por lo tanto se puede predicar de todos los hombres con igual intensidad, no puede llegar a perderse en ninguna circunstancia, es la fuente inmediata de los derechos fundamentales y cualquier acto contrario a ella, es decir a los derechos que de ella se derivan, genera un deber de reparación (pp. 623-624).

* Presentados por los magistrados Marco Gerardo Monroy Cabra y Rodrigo Escobar Gil.

** Se hacen correcciones ortográficas al texto original.

*** Cursivas presentes en el texto original.

Fuente: elaboración propia.

"antes del nacimiento", lo que de forma clara se relaciona con el no nacido. $\mathrm{Y}$, en tercer lugar, se prohíben las acciones violentas que atenten contra la vida.

Es de anotar que frente a los planteamientos de la Sentencia C-355 de 2006 surgieron diferentes aclaraciones y salvamentos de voto que muestran la tensión cuando se hace referencia al significado y al valor que se le concede al nasciturus, pero a su vez cuando se pondera su protección y derechos frente a los de su propia madre. Ambas partes - los que defienden la despenalización del aborto por las tres causales y los que la rechazan (salvamentos) presentan sus argumentos basados en la dignidad y el derecho a la vida de la mujer y del nasciturus (tabla 1).

La legislación colombiana le concede el derecho a la vida a la persona humana y la protección de la vida la garantiza incluso a quienes no han nacido. La vida como valor o derecho no tiene un carácter absoluto y por esta razón se despenaliza el aborto por las tres razones conocidas. De esta forma, es competencia del Estado y por tanto declara la inexequibilidad de la prohibición total del aborto en Colombia de acuerdo con la Sentencia C-355 de 2006 se da porque:

La interrupción del embarazo no es abordada por nuestro ordenamiento constitucional como un asunto exclusivamente privado de la mujer embarazada y por lo tanto reservada al ámbito del ejercicio de su derecho al libre desarrollo de la personalidad (...) las decisiones que adopte la mujer embarazada sobre la interrupción de la vida en gestación trascienden de la esfera de su autonomía privada e interesan al Estado y al legislador (pp. 282-283).

\section{Sentencia $.^{\circ} \mathrm{C}-327$ de 2016}

Presenta el más reciente pronunciamiento de la Corte Constitucional colombiana frente a la demanda que pide declarar la inexequibilidad de la expresión "la existencia legal de toda persona principia al nacer" del artículo 90 del Código Civil, porque permite que el nasciturus sea tratado como objeto al quedar desprovisto de la dignidad humana inherente a todo ser humano concebido, y desconoce el artículo 4 de la Convención Americana de Derechos Humanos, que establece que la 
vida inicia con la concepción. En su fallo, la Corte declara la exequibilidad de dicha expresión bajo los siguientes argumentos:

La determinación de la existencia legal de la persona desde el nacimiento no viola el deber de protección de la vida desde la concepción, establecido en el artículo 4.1. de la Convención Americana, ya que la vida como valor es un bien constitucionalmente relevante, pero no tiene el mismo grado de protección que el derecho a la vida. La expresión acusada del artículo 90 del Código Civil tiene en cuenta esta realidad, la cual a su vez protege otros derechos en juego. Por lo tanto, una lectura sistemática del bloque de constitucionalidad indica que la vida prenatal no ostenta la titularidad del derecho a la vida y así la determinación de la existencia legal de la persona desde el nacimiento, no viola esta garantía por lo que se encuentra ajustada a los parámetros constitucionales.

\section{Conclusiones}

El derecho, como punto de partida para abordar lo referente al nasciturus, refleja que las medidas establecidas desde la parte jurídica han estado presentes en diferentes épocas y contextos reglamentando los límites y alcances de los derechos del nasciturus y también las obligaciones de todas las personas, las instituciones y el Estado hacia él.

Las legislaciones presentadas permiten evidenciar que el no nacido en la antigüedad ocupaba un rol importante en la organización social, en la distribución económica dentro de la familia, especialmente cuando había bienes patrimoniales que demandaban sucesiones, además que su significado estaba influenciado por la concepción religiosa. El nasciturus también cobraba relevancia cuando su vida era afectada o interrumpida por razones violentas o de negligencia por cuenta de otros. En consecuencia, el daño producido por terceros, incluso por su misma madre -independientemente del método utilizado-, era considerado una falta establecida y regulada por la ley con sus respectivas consecuencias económicas, sociales, civiles y morales según el caso particular.

En relación con la legislación colombiana, esta establece que la vida no es un valor absoluto y que existe una diferencia entre el derecho a la vida y la vida como bien constitucionalmente protegido. El derecho a la vida es otorgado a las personas que adquieren esta condición a partir del momento del nacimiento, a diferencia del nasciturus, que, en su condición de persona potencial, se le garantiza únicamente la protección de su vida por ser esta un bien constitucionalmente protegido.

Esta determinación ha generado innumerables controversias y opiniones especialmente en lo que respecta al tema del aborto, porque se pone en consideración no solo el estatuto jurídico del nasciturus, sino también el estatuto moral sobre cuándo comienza la persona humana a existir, cuáles derechos le corresponden y si se está teniendo en cuenta su dignidad, entre otros aspectos.

El Estado tiene la obligación de proteger al nasciturus con el fin último de hacer posible el nacimiento de aquel en las mejores circunstancias, es decir, haciendo posible que llegue a ser persona en estricto sentido jurídico. De la misma forma, y precisamente por la condición de vulnerabilidad del nasciturus, el Estado, por mandato constitucional, está en la obligación de adecuar todos los elementos y poner en marcha todos los mecanismos para evitar que el no nacido pueda perder la vida. Esto incluye la satisfacción de las necesidades básicas de la madre gestante, la protección y asistencia frente a situaciones de riesgo como aquellas generadas por causa del conflicto armado.

En síntesis, podemos afirmar que, a través de la promulgación de diversas leyes, códigos y sentencias, y tomando como referentes los tratados, convenciones y acuerdos de carácter internacional que le competen, basándose siempre en la Constitución, el Estado colombiano debe asumir el mandato de cuidar y proteger al nasciturus. Sin embargo, los testimonios en escenarios de guerra y violencia y que reflejan algún tipo de afectación hacia el no nacido demuestran que la realidad es otra.

El nasciturus, desde la perspectiva jurídica, no puede ser considerado víctima de forma directa, por las restricciones que tiene al no ser persona legalmente reconocida. Sin embargo, por el deber 
de protección de la vida humana como bien constitucional el Estado debe al nasciturus la protección correspondiente, protección que compromete a las personas, en un grado aún más exigente en aquellas situaciones en las que, por efecto del conflicto, su vida pudiera estar en peligro.

\section{Referencias}

Alisté, T. (2011). Tutela judicial efectiva del nasciturus en el proceso civil. Barcelona: Atelier.

Asamblea Nacional Constituyente. República de Colombia. (1991). Constitución Política de Colombia.

Biblioteca Legum. (s.f.). Lex Romana Visigothorum. Recuperado de http://www.leges.uni-koeln.de/en/lex/ lex-romana-visigothorum/

Cárdenas, O. C. y Sierra-Torres, C. H. (2004). El concepto legal de persona en Colombia. Revista de Derecho y Genoma Humano. Genética, Biotecnología y Medicina, (20), 65-90.

Congreso de la República de Colombia. (1887). Ley n. ${ }^{\circ}$ 57 de 1887. Código Civil Colombiano. Recuperado de http://www.alcaldiabogota.gov.co/sisjur/normas/Norma1.jsp?i=39535

Congreso de la República de Colombia. (1980). Decreto Ley 100 de 1980. Diario Oficial n. ${ }^{\circ} 35.461$ de 20 de febrero de 1980. Código Penal Colombiano. Recuperado de http://www.icbf.gov.co/cargues/avance/docs/codigo_penal_1980.htm

Congreso de la República de Colombia. (2000). Ley n. ${ }^{\circ} 599$ de 2000. Diario Oficial no. 44.097 de 24 de julio del 2000. Por la cual se expide el código penal. Recuperado de http://www.secretariasenado.gov.co/senado/basedoc/ley_0599_2000.html

Corte Constitucional. República de Colombia. (1994). Sentencia n. ${ }^{\circ}$ C-133 de 1994. Recuperado de http://www.corteconstitucional.gov.co/RELATO RIA/1994/C-133-94.htm

Corte Constitucional. República de Colombia._(1995). Sentencia $n .{ }^{\circ}$ C-591 de 1995. Recuperado de http://www.corteconstitucional.gov.co/RELATO RIA/1995/C-591-95.htm

Corte Constitucional. República de Colombia. (1997). Sentencia n. ${ }^{\circ}$ C-013 de 1997. Recuperado de http://www.corteconstitucional.gov.co/RELATO RIA/1997/c-013-97.htm

Corte Constitucional. República de Colombia. (1998). Sentencia n. ${ }^{\circ}$ T-223 de 1998. Recuperado de http://www.corteconstitucional.gov.co/relatoria/1998/T-223-98.htm
Corte Constitucional. República de Colombia. (2006). Sentencia $n .{ }^{\circ}$ C-355 de 2006. Recuperado de http://www. corteconstitucional.gov.co/relatoria/2006/c-355-06.htm

Corte Constitucional. República de Colombia. (2016). Sentencia n. ${ }^{\circ}$ C- 327 de 2016. Recuperado de http://www.corteconstitucional.gov.co/RELATORIA/2016/C-327-16.htm

Corral, H. (2017). El estatus del embrión humano. Humanitas. Recuperado de http://www.humanitas.cl/bioetica/el-estatus-del-embrion-humano-hernan-corral

De Castro y Bravo, F. (1991). La persona jurídica. Madrid: Civitas.

Díaz, G. (2006). La concepción "totémica" del "nasciturus" en la jurisprudencia del tribunal constitucional. Persona $y$ derecho, 54 (185-212).

Ezquerra, A. (2009). Las enciclopedias en España antes de l'Encyclopédie. Editorial csic Press. Recuperado de https://books.google.com.co/books

França-Tarragó, O. (2008). Bioética en el principio de la vida. Buenos Aires: Paulinas.

History. Se promulgó la Ley Sálica. Recuperado de: http:// co.tuhistory.com/search/node/ley\%20salica

Hoyos, I. (2000). La persona y sus derechos. Consideraciones bioético jurídicas. Santa Fe de Bogotá: Temis.

Maldonado y Fernández del Torco, J. (1946). La concepción jurídica del "nasciturus" en el derecho español. Madrid: Ministerio de Justicia y Consejo Superior de Investigaciones Científicas.

Matthews, V. y Benjamin, D. (2004). Paralelos del Antiguo Testamento: leyes y relatos del Antiguo Oriente Bíblico. Bilbao: Sal Terrae.

Montoya, G. (2004). Segundo Congreso Internacional de Derecho de Familia. Recuperado de http://www.udea.edu. co/wps/portal/udea/web/generales/interna/lut/p/z0/

Porras del Corral, M. (2005). "Persona y dignidad desde el derecho”. En: J. Masiá (Ed.), Ser humano, persona y dignidad (pp. 199-244). Bilbao: Universidad Pontificia Comillas.

Romeo, C. (2002). Los genes y sus leyes. El derecho ante el genoma humano. Bilbao, España: Cátedra Universitaria Fundación вBVA.

Starck, C. (2006). El estatuto moral del embrión. (Spanish). Revista Selecciones de Bioética, (10), 69-77.

Ugarte, J. (2017). El aborto es siempre un crimen. ¿Por qué? Humanitas. Recuperado de http://www.humanitas.cl/ bioetica/el-aborto-es-siempre-un-crimen-por-que-j-jugarte-26-01-2017 
